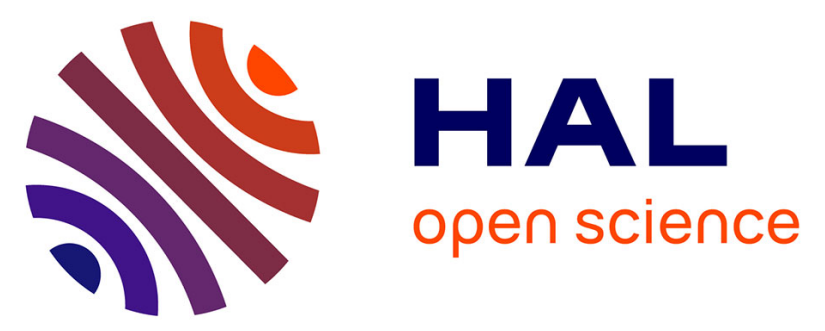

\title{
Polynucleotide transport through lipid membrane in the presence of starburst cyclodextrin-based poly(ethylene glycol)s
}

Z. Eskandani,, Tony Le Gall, Tristan Montier, Pierre Lehn, Fabien Montel, Loïc Auvray, Cécile Huin, Jean-Philippe Guegan

\section{To cite this version:}

Z. Eskandani,, Tony Le Gall, Tristan Montier, Pierre Lehn, Fabien Montel, et al.. Polynucleotide transport through lipid membrane in the presence of starburst cyclodextrin-based poly(ethylene glycol)s. European Physical Journal E: Soft matter and biological physics, 2018, 41 (11), pp.132. 10.1140/epje/i2018-11743-3 . hal-01969985

\section{HAL Id: hal-01969985 \\ https://hal.sorbonne-universite.fr/hal-01969985}

Submitted on 4 Jan 2019

HAL is a multi-disciplinary open access archive for the deposit and dissemination of scientific research documents, whether they are published or not. The documents may come from teaching and research institutions in France or abroad, or from public or private research centers.
L'archive ouverte pluridisciplinaire HAL, est destinée au dépôt et à la diffusion de documents scientifiques de niveau recherche, publiés ou non, émanant des établissements d'enseignement et de recherche français ou étrangers, des laboratoires publics ou privés. 


\section{Polynucleotide Transport through Lipid Membrane in the Presence of Starburst Cyclodextrin-Based Poly(Ethylene Glycol)s}

Zahra Eskandani ${ }^{a, b}$, Tony Le Gall ${ }^{c, d}$, Tristan Montier ${ }^{c, d, e}$, Pierre Lehn ${ }^{c}$, Fabien Montelf, Lö̈c Auvray ${ }^{f}$, Cécile Huin ${ }^{a, b}$ and Philippe Guégan ${ }^{g^{*}}$

a'LAMBE, Univ Evry, CNRS, CEA, Université Paris-Saclay, 91025 Evry, France

'LAMBE, Université Cergy-Pontoise, Université Paris-Seine, 91025 Evry, France

'INSERM UMR 1078; Faculté de Médecine, Université de Bretagne Occidentale; Université Européenne de Bretagne, 22 avenue Camille Desmoulins, 29238 Brest Cedex 3, France

'Plateforme SynNanoVect, Biogenouest, SFR 148 ScInBioS; Université de Bretagne

Occidentale, Faculté de Médecine, 22 avenue Camille Desmoulins, 29238 Brest Cedex 3, France

'Laboratoire de génétique moléculaire et d'histocompatibilité, CHRU de Brest, 5 avenue du Maréchal Foch, 29609 Brest Cedex 3; DUMG, Université de Bretagne Occidentale, Faculté de Médecine, 22 avenue Camille Desmoulins, 29238 Brest Cedex 3, France

${ }^{\mathrm{f}}$ Matière et Systèmes Complexes, CNRS-UMR 7057, Université Paris-Diderot, 10 rue Alice Domon et Léonie Duquet, 75205 Paris cedex 13, France

${ }^{\text {g}}$ Sorbonne Université, CNRS, Institut Parisien de Chimie Moléculaire, Equipe Chimie des

Polymères, 4 place Jussieu, F-75005 Paris, France

\section{Corresponding Author}

*philippe.guegan@sorbonne-universite.fr

ABSTRACT. Symmetrical cyclodextrin-based 14-arm star polymers with poly(ethylene glycol) PEG branches were synthesized and characterized. Interactions of the star polymers with lipid bilayers were studied by the 'black lipid membrane' technique in order to demonstrate the formation of monomolecular artificial channels. The conditions for the insertion are mainly based on dimensions and amphiphilic properties of the star polymers, in particular the molar mass of the water-soluble polymer branches. Translocation of single strand DNA (ssDNA) through those synthetic nanopores was investigated, and the close dimension between the cross- 
section of ssDNA and the cyclodextrin cavity led to an energy barrier that slowed down the translocation process.

Keywords: Polymers: From Adsorption to Translocation - Topical Issue in Memoriam Loïc Auvray (1956-2016)

\section{Introduction}

Translocation of molecules and macromolecules through lipid bilayers remains a challenging task for applications such as drug delivery, information, transportation... The most efficient tools to achieve this task are artificial channels inserted into lipid membranes. Beside their transportation activity, they can also be involved in the synthesis of proteins through ribosome, ${ }^{1}$ synthesis of cellulose in 'rosette' complexes, ${ }^{2}$ protein folding and misfolding. ${ }^{3}$ Common translocated macromolecules are DNA, ${ }^{4}$ RNA, ${ }^{5}$ proteins, ${ }^{6}$ polyelectrolytes, ${ }^{7}$ polysaccharides, ${ }^{8}$ neutral polymers, ${ }^{9}$ leading to many applications. ${ }^{10}$ Biological nanopores (aerolysin, $\alpha$ hemolysin), ${ }^{11}$ solid-state nanopores (glass, graphene, $\left.\mathrm{Si}_{3} \mathrm{~N}_{4}\right)^{4 \mathrm{~b}, 12}$ and synthetic nanopores ${ }^{13}$ have been reported to allow translocation of macromolecules one by one. Though artificial nanochannels may exhibit substantial interests such as well-defined, well-controlled and reproducible size at the nanometer scale, translocation through those nanopores has been scarcely studied. ${ }^{14}$

Artificial channels are obtained by using amphiphilic compounds inserted into a lipid bilayer, formed by self-assembly of either peptides (oligo- or cyclic peptides) ${ }^{15}$ or modified cyclic scaffolds like calixarene, resorcinarene, crown-ether, curcubituril, pillar[n]arene, or cyclodextrin (CD). ${ }^{16}$ The macrocycles determine the internal nanopore diameter, unlike ill-defined pores achieved by amphiphilic copolymers interacting with lipid bilayers. ${ }^{17}$ Large effort was made to study mass transport through artificial nanopores by using small molecules such as ions or amino acids, providing even selectivity (or permeability) functions. ${ }^{16 c, 18}$ In these studies, the diameter of the artificial nanopores was close to the one of the translocating molecules. Translocation/transport of macromolecules through a sub-nanometer scale artificial nanopore remains a challenge. Indeed, the hydrodynamic volume of the macromolecules is much higher than any section of the reported artificial channels and the entropic force for the confinement of macromolecules has to be overcome. 
The ease of $\mathrm{CD}$ chemical modifications ${ }^{19}$ allowed the synthesis of a large artificial channel family ${ }^{16}$ forming, for most of them, transient artificial channels. CD-based star polymers could provide the opportunity to increase the lifetime of the channels, a property that may facilitate the translocation of macromolecules. Furthermore, it has been suggested that the CD cavity is large enough to allow the translocation of a single strand DNA (ssDNA) ${ }^{20}$ Herein, we investigate the ability of CD-based synthetic polymers (Scheme 1) to form artificial nanochannels/nanopores in a lipid bilayer, and study the translocation of a single strand oligonucleotide through a lipid bilayer in the presence of these CD-based synthetic polymers.
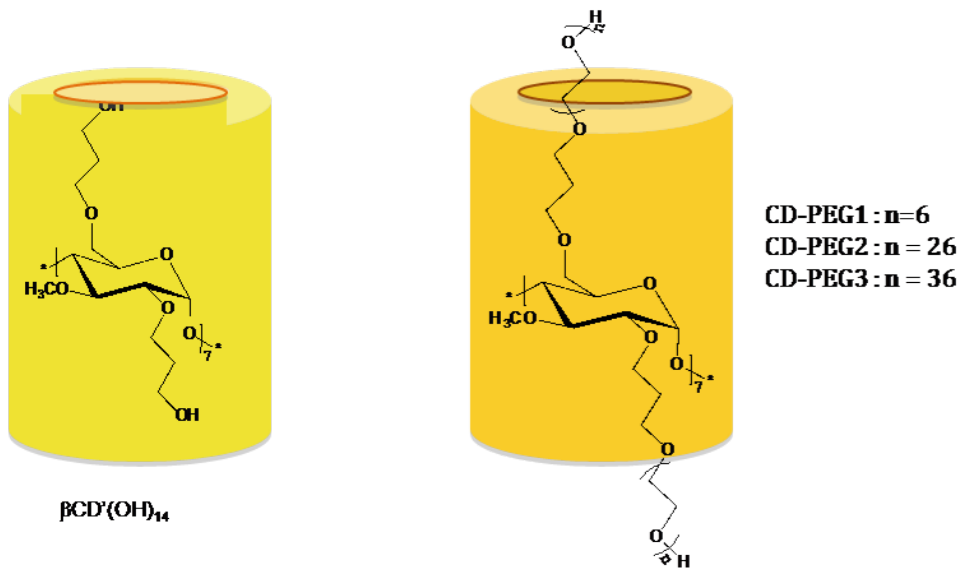

Scheme 1. 14-arm PEG star polymers initiated by $\beta \mathrm{CD}^{\prime}(\mathrm{OH})_{14}$. 


\section{Experimental Section}

1.1. Synthesis and characterization of the 14-arm star polymers based on $\beta$-cyclodextrin.

The protocol to synthesize the star polymers has previously been described. ${ }^{21}$ Typically, per(2,6-di-O-(3-hydroxypropyl)-3-O-methyl)- $\beta$-CD was synthesized in a three step procedure ${ }^{22}$ then carefully dried. ${ }^{21}$ Ethylene oxide (Aldrich) and DMF were purified using standard procedures. $^{21}$ All vessels were flamed under high vacuum, prior to use. The solvent was vacuumdistilled from $\mathrm{CaH}_{2}$ in a $100 \mathrm{~mL}$ burette. Then, half of the solvent was distilled in the burette containing the base, diphenylmethylpotassium, DPMK. The other half was distilled in the burette containing the $\mathrm{CD}$ initiator. A $250 \mathrm{~mL}$ four-neck flask equipped with a magnetic stirrer was surmounted with three burettes containing respectively the ethylene oxide monomer, the initiator and DPMK, both in DMF. All the burettes were then put under high vacuum (after flaming the reactor wall). The solution of $\mathrm{CD}$ derivative was first introduced in the reactor, followed by the slow addition of the DPMK solution. The obtained homogeneous solution was stirred during 48h at room temperature. The reactive mixture was then cooled to $0^{\circ} \mathrm{C}$ in order to add the ethylene oxide monomer in a drop wise manner. The polymerization was then carried out at $40^{\circ} \mathrm{C}$ and the reaction was quenched by addition of acidic methanol. After concentration of the polymerization medium, the polymer was precipitated successively in cold ether and pentane, in order to remove some linear homopolymer from initiation with water entrapped in the CD derivative. ${ }^{21}$

NMR spectra and DOSY experiments ${ }^{23}$ were recorded on a Bruker Advance AM300 spectrometer $\left({ }^{1} \mathrm{H} 300 \mathrm{MHz}\right.$ and $\left.{ }^{13} \mathrm{C} 75 \mathrm{MHz}\right)$ using DMSO-d $\mathrm{d}_{6}$ as solvent at $25^{\circ} \mathrm{C}$. The molar masses were determined by size exclusion chromatography (SEC) with DMF as eluent, the concentration of the polymer being $3 \mathrm{mg} \cdot \mathrm{mL}^{-1}$ (Electronic Supplementary Material ESM Fig.S13).

\subsection{Interactions with a model membrane.}

The interactions of polymers with a model membrane were studied according to an electrophysiological technique, currently used in the laboratory ${ }^{24}$ (ESM Fig.S4). A film of a $1 \%$ solution of diphytanoylphosphatidylcholine in decane was spread across a $150 \mu \mathrm{m}$ wide hole, drilled in a Delrin wall separating two chambers of a measurement device. Each chamber contained $1 \mathrm{~mL}$ of a $1 \mathrm{M}$ (or $3 \mathrm{M}) \mathrm{KCl}, 5 \mathrm{mM}$ HEPES ( $\mathrm{pH} 7.4$ ) solution. After thinning of the decane film in order to get a planar bilayer, electric current measurements were performed. 
Before each experiment, the capacity of the membrane was measured in order to provide an estimation of the membrane thickness. Star polymers from a stock solution were added in both chambers, at controlled concentrations. Then, a voltage was applied to the lipid bilayer to assess the formation of channels through the membrane. Parameters of prime importance, such as thickness of the membrane (around $5 \mathrm{~nm}$ ) and star polymer concentration in the chambers $(0.2 \mu \mathrm{M})$, were controlled.

Data acquisition: The ionic current through the membrane was measured with a BLM 120 amplifier (Biologic). Data were acquired at $1,500 \mathrm{~Hz}$ and filtered at $300 \mathrm{~Hz}$ with the Measurement Computing Digitizer, in order to minimize the noise. In the absence of channels in the membrane, no current intensity was detected between the two compartments under an applied voltage. When a transient or permanent channel was formed, a current intensity could be recorded, demonstrating the formation of the pore.

1.3. Evidencing DNA translocation from trans to cis chambers: detection and quantification.

A 136-nucleotide (nt) long single strand DNA (ssDNA) was used in our experiments. Its sequence (5'-CGC-TCC-TAC-CTG-TCG-CTC-CTT-AC-[TAC-GCT] $]_{15}$-CCC-AAC-TCT-GATACG-GCA-TAC-TT-3') was designed.

Each chamber was filled with $1 \mathrm{~mL}$ of a $3 \mathrm{M} \mathrm{KCl,} 5 \mathrm{mM}$ HEPES (pH 7.4) solution, in order to have a good signal to noise ratio. Once the membrane formed, $10 \mu \mathrm{L}$ of ssDNA at $10 \mu \mathrm{M}$ $\left([\mathrm{ssDNA}]_{\mathrm{f}}=0.1 \mu \mathrm{M}\right)$ was added in the trans chamber and CD-PEG1 was added in both chambers, a $-100 \mathrm{mV}$ voltage being applied to help the translocation. After various acquisition times, the solutions in the chambers were carefully withdrawn and 4 samples (cis/trans) were tested for quantitative PCR (qPCR). Between each experiment, both chambers were carefully washed with $0.1 \mathrm{M} \mathrm{NaOH}$ and $0.1 \mathrm{M} \mathrm{HCl}$, to get rid of ssDNA residues. Measurement without CD-PEG1 (blank experiments) were carried out to validate the procedure.

The PCR reactions were performed using primers specifically annealing to the ssDNA (forward primer: 5'-TCC-TAC-CTG-TCG-CTC-CTT-AC-3'; reverse primer: 5'-TAT-GCC-GTA-TCAGAG-TTG-GG-3'), thereby leading to the amplification of a 130-base pair long specific PCR product. Absolute quantifications were carried out to estimate the ssDNA translocation efficacy from trans to cis chambers. For this purpose, serial dilutions were prepared to estimate, by real- 
time qPCR, the amount of ssDNA in each chamber, using the QuantiTect SYBR Green PCR kit (Qiagen, Chatsworth, CA, USA), in accordance with the manufacturers' recommendations.

2. Results and Discussion

Amphiphilic star polymers with 14 poly(ethylene glycol) (PEG) arms and a $\beta$-cyclodextrin ( $\beta$ CD) core were synthesized by a living "grafting from" polymerization of ethylene oxide initiated by per(2,6-di-O-(3-hydroxypropyl)-3-O-methyl)- $\beta$ - $\mathrm{CD}\left(\beta \mathrm{CD}^{\prime}(\mathrm{OH})_{14}\right)$ as previously reported. Molecular characteristics of CD-PEG2 are reported in the Electronic Supplementary Material as an illustration (ESM Table 1, Fig.S1-S3). ${ }^{21}$ The architecture of the star polymers was designed in order to form a symmetrical channel, with a hydrophobic core able to insert within the hydrophobic part of the lipid membrane. Hydrophilic arms were used to obtain water-soluble macromolecules.

The interactions of $\beta \mathrm{CD}^{\prime}(\mathrm{OH})_{14}$ and the different 14-arm star polymers with lipid bilayers were investigated by the 'Black Lipid Membrane' (BLM) technique (experimental set-up described in ESM Fig.S4). ${ }^{24}$ Typically, the lipid membrane behaves as an insulator when an electrical difference of potential of about $+/-100 \mathrm{mV}$ is applied. A current is detected when the lipid membrane is perturbed. Current versus time traces and current distribution (occurrence versus current) allow the detection of events (current jumps) corresponding to either insertion of single artificial channel (discrete signal), or interactions, or formation of ill-defined aggregates in the membrane.

First, the interactions of $\beta \mathrm{CD}^{\prime}(\mathrm{OH})_{14}$ with lipid bilayers were investigated. Indeed, it is well established that cyclic peptides are able to self-assemble to form non-covalent nanotubes within a lipid bilayer with dimension compatible with the thickness of a lipid bilayer. ${ }^{15}$ Whatever the concentration of $\beta C D^{\prime}(\mathrm{OH})_{14}$ introduced in both chambers of the BLM set-up, no current change was detected: neither interaction, nor insertion was observed (ESM Fig.S5).

Then, the ability of the star polymers to form artificial channels was investigated. First, the acquisition parameters were set according to previous works, which demonstrated the translocation of ssDNA through $\alpha$-hemolysin..$^{5 c, 25}$ Interestingly, the signal to noise ratio reaches intensity value incompatible with the detection of nanochannel insertion, as reported by Fyles et coll.. ${ }^{26}$ Then, the data were acquired at $1,500 \mathrm{~Hz}$ and filtered at $300 \mathrm{~Hz}$, in order to demonstrate the presence of single-molecule artificial channels inserted in the lipid membrane, without pollution from aggregates. The current versus time traces obtained when CD-PEG1 $\left(X_{\mathrm{n}}=6\right)$ was 
used at a concentration of $0.2 \mu \mathrm{M}$ in both chambers of the BLM set up, at $\mathrm{pH}=7$, is presented in Figure 1.
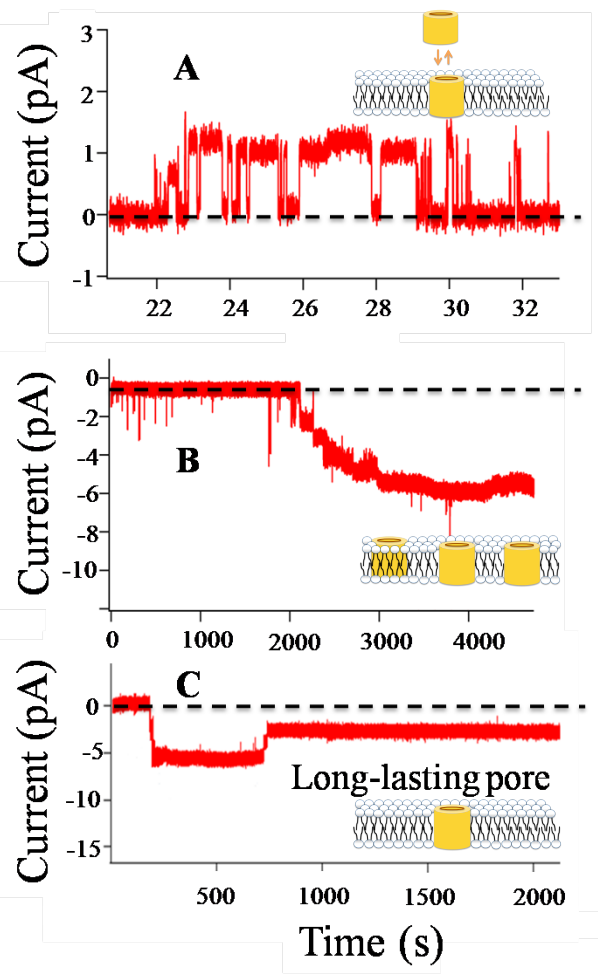

Figure 1. Evidence of insertion of CD-PEG1 in a lipid bilayer $(0.2 \mu \mathrm{M}-\mathrm{KCl} 1 \mathrm{M})$

A-Current-time traces for an applied voltage of $100 \mathrm{mV}$

B/C-Current-time traces for an applied voltage of $-100 \mathrm{mV}$.

Three typical distinct results are reported. In the first experiment (Fig.1-A), consecutive discrete conductance events, attributed to the insertion and the pulling out of CD-PEG1 in the lipid bilayer, are observed. The histogram of the number of events at each current revealed two populations of current events separated by 1 pA for an applied voltage of $100 \mathrm{mV}$ (ESM Fig.S6A). The population of events centered at $0 \mathrm{pA}$ was attributed to unperturbed membrane, while the one centered at $1 \mathrm{pA}$ was attributed to the formation of single-molecule artificial channels. In the second experiment (Fig.1-B), the current versus time decreases in an incremental way, reflecting the insertion of multiple artificial channels. A distribution of peaks separated by $1 \mathrm{pA}$ is observed in the histogram from experiment B (ESM Fig.S6-B). Plotting these intensity maximum of the histogram as a function of number of inserted pores at the same time, allows for a linear relationship, supporting our conclusion (ESM Fig.S6-C). A linear fit can be applied, and 
a slope value of $1 \mathrm{pA} /$ current peak was again obtained, which validated the hypothesis of simultaneous insertion of artificial channels in the lipid bilayer. The measured value of the conductance was in accordance with the one obtained with other cyclodextrin-based artificial channels. ${ }^{16 \mathrm{~d}} \mathrm{I}-\mathrm{V}$ plot of CD-PEG1 (single nanochannel, ESM Fig.S6-D) is fitted by a linear relationship, demonstrating that no rectification of the pore occurred. An apparent nanopore diameter value close to $1 \AA ̊$ was calculated using the Ohm law, value much lower than a native

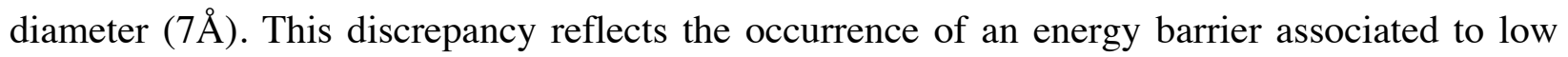
dielectric constant of the nanopore, reducing the transport of ions through the artificial channel. ${ }^{24 \mathrm{~b}}$ In addition, when the conductance is lower than $100 \mathrm{pS}$, it is no longer significant to use this value to calculate the radius of the nanopores. ${ }^{26}$ The $7 \AA$ diameter of the native CD must thus be considered, even if the hydrogen bond ring of the CD is lost for the CD-PEG family, providing then some flexibility to the macrocycle.

In the third typical record of the BLM experiment for CD-PEG1 (Fig.1-C), a discrete increase of the current to about $1 \mathrm{pA}$ is observed, and lasts for more than hundreds of seconds. A possible occurrence of artificial channels with a long lifetime is then concluded.

Considering the large range of the artificial channel lifetime (from seconds to more than one hour), it was difficult to investigate the correlation between CD-PEG1 concentration and pore duration. However, the CD-PEG1 architecture and the distribution of the hydrophilic and hydrophobic parts of the macromolecules recalled the ones used by Lehn and co-workers, ${ }^{16 \mathrm{~b}}$ suggesting the formation of monomolecular transmembrane artificial channels. The lifetime of CD-PEG1 is much longer than that measured for pore-forming $\alpha$-hemolysin containing a cyclodextrin adapter (close to $10 \mathrm{~s}$. .). ${ }^{20} \mathrm{CD}$-PEG1 could then be an alternative to engineered $\alpha$ hemolysin, produced to favor a tight binding of CD inside these mutants. ${ }^{27}$

The influence of the star polymer arm molecular weight upon insertion of these compounds in the lipid bilayer was investigated. Undefined electrical signals were recorded for the star polymers CD-PEG2 $\left(X_{\mathrm{n}}=26\right.$, ESM Fig.S7) and CD-PEG3 ( $X_{\mathrm{n}}=36$, ESM Fig.S8), at a concentration of $0.2 \mu \mathrm{M}$. Analysis of the current versus time records suggested the presence of different kinds of events: aggregated species, undefined interactions and permeabilization of the membrane, shown by an abrupt intensity decrease at the end of the recordings (ESM Fig.S7-B, Fig.S8-C). The nature of the interactions between CD-PEGs and lipid membrane was then molecular weight-dependent and seems to follow the well-known example of $\alpha$-hemolysin 
heptamer. Its insertion occurred by the rigid 'stem' part and not by the folded chain 'cap' of the heptamer, sterically-prevented. Large $X_{\mathrm{n}}$ of CD-PEG leads to folded PEG arms that form a cap at both sides of the CD channel, preventing from their insertion in the lipid bilayer. For CD-PEG1, the molar mass of the PEG arms was low enough to be stretched and allowed its insertion in the lipid membrane. ${ }^{28}$

The demonstration that CD-PEG1 forms unitary nanochannels led us to investigate whether these channels could allow the translocation of a macromolecule through a lipid model membrane. First, data were acquired at $300 \mathrm{kHz}$ and filtered at $100 \mathrm{kHz}$, in order to meet the expected dwell time of macromolecule translocation. As already mentioned, the artificial channel insertion signal was lost in the noise signal, preventing then from any blockade amplitude recording. Data were thus acquired at $1,500 \mathrm{~Hz}$ and filtered at $300 \mathrm{~Hz}$. A blockade amplitude recording was then impossible due to the filtering process. However, one could detect the presence/absence of single-molecule artificial channels, discriminated from aggregates inserted in the lipid bilayer. At first, various poly(ethylene glycol)s or dextran sulfate polymers were added in the trans chamber in order to study their translocation through the lipid bilayer in the presence of CD-PEG1. No blockade amplitude was detected, as expected, and the translocation of those macromolecules could not be evidenced. Futhermore, discrimination between artificial channel removal from the lipid bilayer, and large blockade cannot be discriminated at these intensity levels. Proving effective translocation of macromolecules through cyclodextrin-based nanopores implied thus to use another, indirect method. DNA, which is detectable using highly sensitive Polymerase Chain Reaction, was then used as a translocating macromolecule. ${ }^{29}$ A 136nucleotide single strand DNA (ssDNA) was designed (ESM Fig.S9) that complied with a series of criteria especially (1) sufficient length allowing for sensitive detection using PCR and (2) a nucleotide sequence preventing any self and cross-annealing (in order to avoid the formation of secondary structures that could have disturbed the translocation through the pore across the membrane). Specific DNA primers (ESM Fig.S10) were used to detect the sequence using quantitative PCR (qPCR). The properties of the primers are given in ESM Table 2.

As a first control for the translocation experiments, a lipid bilayer was formed between the cis and trans chambers, ssDNA was added in the trans compartment and no CD-PEG1 was introduced in the set-up (blank experiment, Exp.1, Figure 2). After 3 hours, a voltage of $-100 \mathrm{mV}$ being applied, the contents of each chamber were carefully collected and were assayed using 
qPCR: the ssDNA concentrations in the trans and cis chambers were evaluated. No ssDNA was detected in the cis chamber, thus validating our sampling procedure and checking that selftranslocation of ssDNA through the membrane was impossible in the described conditions.

A series of experiments were then performed in which CD-PEG1 was added in both chambers at the desired concentrations. The electrical signals were recorded during the translocation experiments, in order to analyze the interactions between the star polymer and the lipid bilayers. Three typical behaviors of CD-PEG1 with the model membrane were observed: unitary nanochannels (Exp.2, ESM Fig.S11), strong (Exp.3, ESM Fig.S12) and weak interactions (Exp.4, ESM Fig.S13). In all those conditions, the qPCR analyses were performed to quantify the ssDNA concentration in cis and trans chambers. Figure 2 gathers the ssDNA quantification (the acquisition time was provided for each experiment).

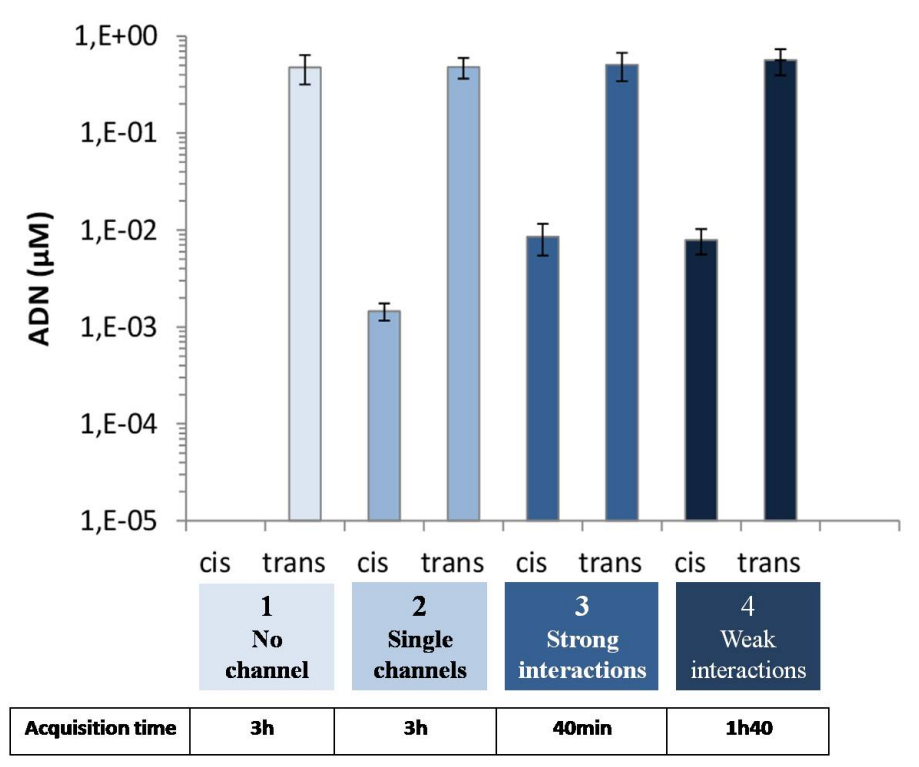

Figure 2. Evidencing ssDNA translocation through the model membrane. Experiments were conducted in absence (1) or in presence (2,3 and 4) of CD-PEG1. ssDNA was added in the trans chamber. After different acquisition times, the ssDNA in the two chambers of the experimental set-up was quantified using qPCR (mean $+/$ - SD with $n=3$ ).

The qPCR analyses showed that the ssDNA remained at a high concentration in the trans chamber. ssDNA was not detected in the cis compartment when no CD-PEG was added in the compartment (blank experiment), as expected. ssDNA was detected in the cis compartment when 
CD-PEG1 was added, whatever the nature of the interactions. Considering that the membrane was not permeable to ssDNA, the diffusion of the polynucleotide through the lipid bilayer must have occurred only via a cavity formed by the CD-PEG1 star polymers. Experiment 2 is however more interesting: ssDNA was evidenced in the cis chamber, while only monomolecular artificial channels are recorded by the BLM measurement. A translocation through the cyclodextrin ring once inserted into the membrane cannot be excluded, since it is the only passage detected.

It is noteworthy here that comparison of the ssDNA quantities must be done carefully when comparing experiments 2,3 and 4 , since the lifetime of the nanochannels, the nature of the permeation structures and the experiment durations were different. However, it is noticeable that when single-molecule artificial channels of CD-PEG1 interacted with the lipid bilayer (Exp.2, Fig.2), the concentration of ssDNA measured in the cis compartment was the lowest, an observation that is actually in good agreement with the smallest size of the synthetic nanopores that have been formed during this experiment. The presence of aggregates, interacting with the lipid bilayer and giving rise to large opening of the lipid membrane (Exp.3), but also the weaker interactions (Exp.4) allowed DNA translocation. It has been demonstrated that PEO arms do not influence the conductivity of the pore, suggesting that ion flux is not perturbed by the polymer arms ${ }^{30}$ However, a role of the arms in the capture of the ssDNA cannot be excluded.

The well-defined size of the artificial channel (i.e. a cyclodextrin cavity) in experiment 2 allowed estimating the ssDNA flow through a single pore as $\mathrm{J}=\mathrm{n}_{\mathrm{DNA}} /\left(\mathrm{P}_{0} \mathrm{t}_{\mathrm{exp}}\right)=3.19 .10^{-14} \mathrm{~mol} . \mathrm{s}^{-1}$ where $\mathrm{n}_{\mathrm{DNA}}$ was the amount of translocated DNA from the trans chamber to the cis chamber, $\mathrm{P}_{0}$ the probability of pore opening and $t_{\exp }$ the duration of the acquisition. This value could not be explained by a simple drift regime $\mathrm{J}_{\text {drift }}=\left(\mathrm{DC}_{0} \mathrm{qV}\right) / \mathrm{L}=1.95 .10^{-7} \mathrm{~mol} . \mathrm{s}^{-1}$ where $\mathrm{D}$ was the selfdiffusion coefficient of DNA, $\mathrm{C}_{0}$ the initial DNA concentration in the trans chamber, $\mathrm{q}$ the effective charge of DNA, V the applied voltage and $L$ the length of the channel. ${ }^{31 a}$ If we assumed that the energy barrier was the limiting step of translocation, it has been shown that $\mathbf{J}_{\text {barrier }}=$ $\left(\mathrm{DC}_{0} \mathrm{~F}\right) \mathrm{e}^{\wedge}(-\mathrm{F}) / \mathrm{L}$ which gave us $\mathrm{F}=12 \mathrm{kT}$ in reasonable agreement with the free energy values that could be estimated from $[\mathrm{CD}] /[\mathrm{DNA}$ base $]$ affinity assays $\left(\mathrm{F}=\log \left(\mathrm{K}_{\mathrm{D}} / \mathrm{C}_{\mathrm{ref}}\right)=7 \mathrm{kT}\right) .{ }^{31}$ Our very simple theoretical framework does not include the internal dynamics of the polymer and then is not influenced by the DNA length but depends linearly on the voltage bias. By construction, these models are not descriptions at equilibrium but rather barrier crossing models working in the kinetic regime. More theoretical investigation is needed to fully characterize our results. 


\section{Conclusions}

The insertion of CD-based star polymers in lipid bilayers was evidenced, depending on the hydrophilic/hydrophobic dimensions of the polymers. The hydrophobic part was chosen to have a size close to the thickness of the lipid bilayer, while $X_{\mathrm{n}}$ of the hydrophilic arms must remain low. Long-lasting nanochannels in lipid bilayers could be obtained, a requirement for the study of polymer translocation. The size of the cyclodextrin scaffold was compatible to the ssDNA cross-section, allowing the translocation of ssDNA through the nanopores. It opens the way to control drug delivery using monomolecular carriers, via new cell internalization processes, or to tune the cell activity, thanks to the creation of a communication path between the various compartments of a cell, cytosol and extracellular medium for example.

\section{ACKNOWLEDGMENT}

This work was partially supported by ANR biograph'n and grants from “Association Française contre les myopathies" (AFM, Evry, France), "Vaincre la Mucoviscidose” (VLM, Paris, France), "Association française de transfusion sanguine et de biogénétique Gaétan Saleün" (Brest, France), INSERM and SFR148ScInBios (Brest, France).

\section{REFERENCES}

1 T. Rapoport, Nature 450, 663 (2007).

2 (a) R.M. Brown Jr, D. Montezinos, Proc.Natl.Acad.Sci. USA 73, 143 (1976); (b) G. Guerriero, J. Fugelstad, V. Bulone, J.Integr.Plant Biol. 52, 161 (2010).

3 C.M. Dobson, Nature 426, 884 (2003).

4 (a) J. Clarke, H.-C. Wu, L. Jayasinghe, A. Patel, S. Reid, H. Bayley, Nature Nanotechnology 4, 265 (2009); (b) G.F. Schneider, S.W. Kowalczyk, V.E. Caldao, G. Pandraud, H.W. Zandbergen, L.M.K. Vandersypen, C. Dekker, Nano Lett. 10, 3161 (2010); (c) T. Auger, J. Mathé, V. Viasnoff, G. Charron, J.-M. Di Meglio, L. Auvray, F. Montel, Phys.Rev.Lett. 113, 028302 (2014); (d) S.E. Henrickson, M. Misakian, B. Robertsin, J.J. Kasianowicz, Phys.Rev.Lett. 85, 3057 (2000).

5 (a) T.Z. Butler, J.H. Gundlach, M.A. Troll, Biophysical Journal 90, 190 (2006); (b) M. Akeson, D. Branton, J.J. Kasianowicz, E. Brandin, D.W. Deamer, Biophysical Journal 77, 3227 (1999); 
(c) J.J. Kasianowicz, E. Brandin, D. Branton, D.W. Deamer, Proc.Natl.Acad.Sci. USA 93, 13770 (1996).

6 (a) G. Oukhaled, J. Mathé, A.-L. Biance, L. Bacri, J;-M. Betton, D. Lairez, J. Pelta, L. Auvray, Phys.Rev.Lett. 98, 158101 (2007); (b) D.S. Talaga, J. Li, J. Am. Chem. Soc. 131, 9287 (2009);

(c) L.J. Siskind, R.N. Kolesnik, M. Colombini, JBC 277, 26796 (2002).

7 S. Ghosal, Phys.Rev.Lett. 98, 238104 (2007).

8 (a) A. Fennouri, R. Daniel, M. Pastoriza-Gallego, L. Auvray, J. Pelta, L. Bacri, Anal.Chem. 85, 8488 (2013); (b) A; Fennouri, C. Przybylski, M. Pastoriza-Gallego, L. Bacri, L. Auvray, R.

Daniel, ACS Nano 6, 9672 (2012).

9 A.G. Oukhaled, A.-L. Biance, J. Pelta, L. Auvray, L. Bacri, Phys.Rev.Lett. 108, 088104 (2012).

10 (a) V.V. Palyulin et al. Nature Biotechnology 26, 1146 (2008); (c) S. Howorka, Z. Siwy,

Chem.Soc.Rev. 38, 2360 (2009); (d) D.W. Deamer, M. Akeson, Trends in biotechnology 18, 147 (2000); (e) M. Wanunu, Physics of Life Reviews 9, 125 (2012).

11 (a) M. Pastoriza-Gallego, L. Rabah, G. Gibrat, B. Thiébot, F. Gisou van der Goot, L. Auvray, J.-M. Betton, J. Pelta, J. Am. Chem. Soc. 133, 2923 (2011); (b) C. Merstorf, B. Cressiot, M. Pastoriza-Gallego, G. Oukhaled, J.-M. Betton, L. Auvray, J. Pelta, ACS Chem.Biol. 7, 652 (2012); (c) L. Payet, M. Martinho, M. Pastoriza-Gallego, J.-M. Betton, L. Auvray, J. Pelta, J. Mathé, J.Anal.Chem. 84, 4071 (2012); (d) R. Kawano, A.E.P. Shibel, C. Cauley, H.S. White, Langmuir 25, 1233 (2009).

12 (a) C. Dekker, Nature Nanotechnology 2, 209 (2007); (b) A. Hemamouche, A. Morin, E. Bourhis, B. Toury, E. Tarnaud, J. Mathé, P. Guégan, A. Madouri, X. Lafosse, C; Ulysse, S. Guilet, G. Patriarche, L. Auvray, F. Montel, Q. Wilmart, B. Plaçais, J. Yates, J. Gierak, Microelectronic Engineering 12, 87 (2014).

13 (a) A.L. Sisson, M. Raza Shah, S. Bhosale, S. Matile, Chem.Soc.Rev. 35, 1269 (2006); (b) N.A.W. Bell, C.R. Engst, M. Ablay, G. Divitini, C. Ducati, T. Liedl, U.F. Keyser, Nano.Lett. 12, 512 (2012); (c) J.R. Burns, K. Göpfrich, J.W. Wood, V.V. Thacker, E. Stulz, U.F. Keyser, S. Howorka, Angew.Chem.Int.Ed. 52, 12069 (2013); (d) J.R. Burns, N. Al-Juffali, S.M. Janes, S. Howorka, Angew.Chem.Int.Ed. 53, 12466 (2014).

14 (a) N. Sakai, S. Matile, J. Am. Chem. Soc. 125, 14348 (2003); (b) C. Huin, T. Le Gall, B. Barteau, B. Pitard, T. Montier, P. Lehn, H. Cheradame, P. Guégan, J.Gene Med. 13, 538 (2011); 
(c) S. Sebai, D. Milioni, A. Walrant, I. Alves, S. Sagan, C. Huin, L. Auvray, D. Massotte, S. Cribier, C. Tribet, Angew.Chem.Int.Ed. 51, 2132 (2012); (d) H. Cho, Y. Zhao, Langmuir 27, 4936 (2011); (e) M. Langecker, V. Arnaut, T.G. Martin, J. List, S. Renner, M. Mayer, H. Dietz, F.C. Simmel, Science 338, 932 (2012).

15 (a) M.R. Ghadiri, J.R. Granja, R.A. Milligan, D.E. McRee, N. Khazanovich, Nature 336, 324 (1993); (b) J. Montenegro, M.R. Ghadiri, J.R. Granja, Acc.Chem.Res. 46, 2955 (2013); (c) M. Danial, C.M.-N. Tran, K.A. Jolliffe, S. Perrier, J. Am. Chem. Soc. 136, 8018 (2014). 16 (a) I. Tabushi, Y. Kuroda, K. Yokota, Tetrahedron Lett. 23, 4601 (1982); (b) M.J. Pregel, L. Jullien, J. Canceill, L. Lacombe, J.-M. Lehn, J. Chem. Soc. Perkin Trans. 2, 417 (1995); (c) N. Madhavan, E.C. Robert, M.S. Gin, Angew. Chem. Int.Ed. 44, 7584 (2005); (d) Y. El Ghoul, R. Renia, I. Faye, S. Rassou, V. Bennevault-Celton, C. Huin, P. Guégan, Chem. Commun. 49, 11647 (2013); (e) H. Mamad-Hemouch, H. Ramoul, M. AbouTaha, L. Bacri, C. Huin, C. Przybylski, A. Oukhaled, B. Thiébot, G. Patriarche, N. Jarroux, J. Pelta, Nano Lett. 15, 7748 (2015); (f) J.K.W. Chui, T.M. Fyles, Org.Biomol.Chem. 12, 3622 (2014); (g) L. Bacri, A. Benkhaled, P. Guégan, L. Auvray, Langmuir 21, 5842 (2005); (h) N. Badi, L. Auvray, P. Guégan, Advanced Materials 21, 4054 (2009).

17 (a) W.H. Binder, Angew.Chem.Int.Ed. 47, 3092 (2008); (b) E. Marie, S. Sagan, S. Cribier, C. Tribet, J.Membrane Biol. 247, 861 (2014).

18 L. Chen, W. Si, L. Zhang, G. Tang, Z.T. Li, J.L. Hou, J. Am. Chem. Soc. 135, 2152 (2013).

19 A.R. Khan, P. Forgo, K.J. Stine, V.T. D’Souza, Chem.Rev. 98, 1977 (1998).

20 (a) L.-Q. Gu, O. Braha, S. Conlan, S. Cheley, H. Bayley, Nature 398, 686 (1999); (b) L.-Q.

Gu, S. Cheley, H. Bayley, J.Gen.Physiol. 118, 481 (2001).

21 C. Huin, Z. Eskandani, N. Badi, A. Farcas, V. Bennevault-Celton, P. Guégan, Carb.Polym. 94, 323 (2013).

22 Z. Eskandani, C. Huin, P. Guégan, Carb.Res. 346, 2414 (2011).

23 V. Bennevault-Celton, A. Urbach, O. Martin, C. Pichon, P. Guégan, P. Midoux, Bioconjugate Chem. 22, 2404 (2011).

24 (a) P. Mueller, D.O. Rudin, H. Ti Tien, W.C. Wescott, Nature 194, 979 (1962); (b) S.M.

Bezrukov, I. Vodyanoy, V.A. Parsegian, Nature 370, 279 (1994); (c) I.G. Abidor, V.B.

Arakelyan, L.V. Chernomordik, Y.A. Chizmadzhev, V.F. Pastushenko, M.R. Tarasevich, Bioelectrochemistry and Bioenergetics 6, 37 (1979). 
25 J. Mathé, A. Aksimentiev, D.R. Nelson, K. Schulten, A. Meller, Proc.Natl.Acad.Sci. USA 102, 12377 (2005).

26 T.M. Fyles, Chem.Soc.Rev. 36, 335 (2007).

27 A. Banerjee, E. Mikhailova, S. Cheley, L.-Q. Gu, M. Montoya, Y. Nagaoka, E. Gouaux, H. Bayley, Proc.Natl.Acad.Sci. USA 107, 8165 (2010).

28 A. Halperin, Langmuir 15, 2525 (1999).

29 J.M.S. Bartlett, D. Stirling, PCR protocols, methods in Molecular Biology, 2nd edition, 226, 3 (2003).

30 P. Prangkio, D.K. Rao, K.D. Lance, M. Rubinshtein, J. Yang, M. Mayer, Biochimica et Biophysica Acta 1808, 2877 (2011).

31 (a) M. Muthukumar, Polymer Translocation, 251 (CRC Press Taylor \& Francis Group, London, New York, 2011); (b) M. Kondo, S. Nishikawa, J. Phys. Chem. B 111, 13451 (2007).

GRAPHICAL ABSTRACT. Artificial Nanopores: Amphiphilic Star Polymers with a $\beta$ cyclodextrin core behave as an artificial nanopore, allowing ssDNA translocation through lipid bilayers

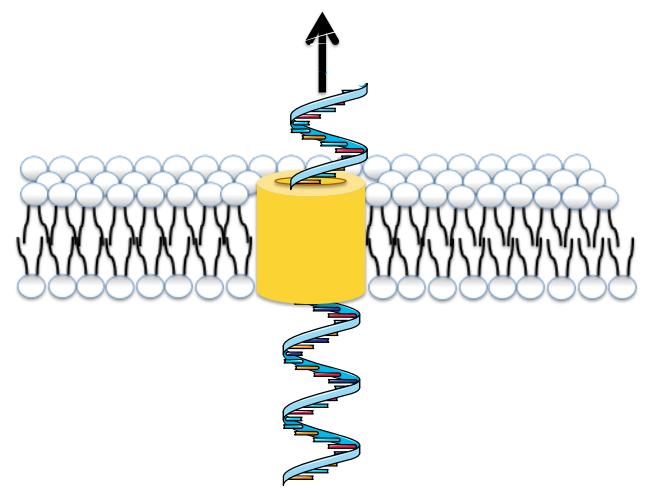




\section{ELETRONIC SUPPLEMENTARY MATERIAL}

Table 1. Star polymer synthesis conditions and molecular characteristics of the 14-arm star polymers $\left([\mathrm{EO}]=2.4 \mathrm{~mol} . \mathrm{L}^{-1}, 40^{\circ} \mathrm{C} \text {, solvent: } \mathrm{DMF}\right)^{21}$

\begin{tabular}{|c|c|c|c|c|c|c|c|}
\hline & $\begin{array}{c}{[\mathrm{OH}]} \\
\left(\mathrm{mol} . \mathrm{L}^{-1}\right)\end{array}$ & $\begin{array}{c}\text { Time } \\
(\text { days })\end{array}$ & $\begin{array}{c}\text { Yield } \\
(\%)\end{array}$ & $\begin{array}{c}\overline{M n} \\
\mathrm{NMR} \\
\left(\mathrm{g} \cdot \mathrm{mol}^{-1}\right)\end{array}$ & $\begin{array}{c}\overline{M n} \text { SEC } \\
\left(\mathrm{g} \cdot \mathrm{mol}^{-1}\right)\end{array}$ & $\begin{array}{c}\overline{X n} \\
(\mathrm{nEO} \text { per } \\
\text { arm })\end{array}$ & PDI \\
\hline$\beta C \mathrm{CD}^{\prime}(\mathrm{OH})_{14}$ & - & - & - & - & - & 0 & - \\
\hline $\mathrm{CD}-\mathrm{PEG}{ }^{*}$ & $1.6 .10^{-2}$ & 7 & 11 & 6600 & 5600 & 6 & 1.14 \\
\hline $\mathrm{CD}-\mathrm{PEG} 2$ & $1.6 .10^{-2}$ & 22 & 36 & 20700 & 18600 & 26 & 1.16 \\
\hline $\mathrm{CD}-\mathrm{PEG} 3$ & $1.6 .10^{-2}$ & 32 & 44 & $\mathrm{nd}$ & 22500 & 36 & 1.01 \\
\hline
\end{tabular}

* $: 12$ arms in average per star, determined by the residual hydroxypropyl signal by ${ }^{13} \mathrm{C}$ NMR.

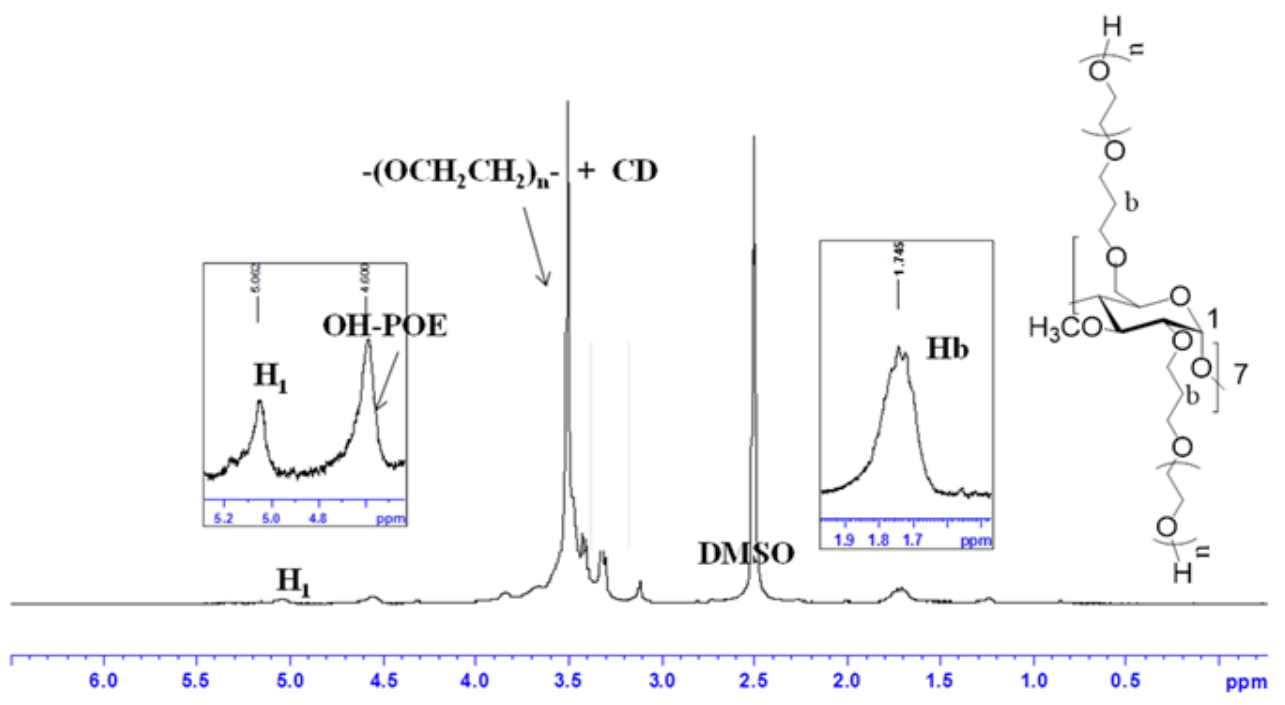

Figure S1. ${ }^{1} \mathrm{H}$ NMR spectrum of CD-PEG2 in DMSO- $\mathrm{d}_{6}{ }^{21}$ 


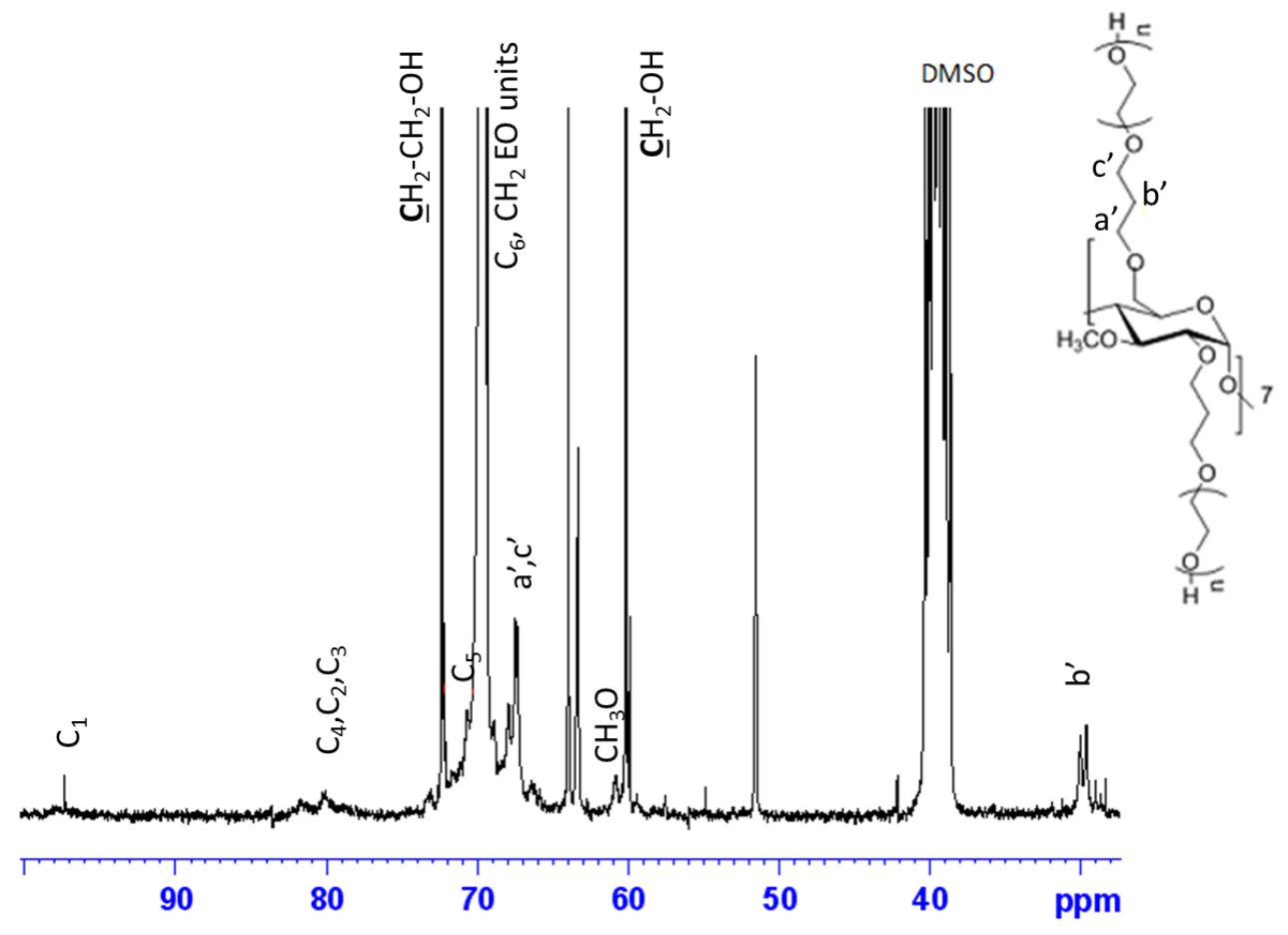

Figure S2. ${ }^{13} \mathrm{C}$ NMR spectrum of CD-PEG2 in DMSO-d ${ }_{6}{ }^{21}$

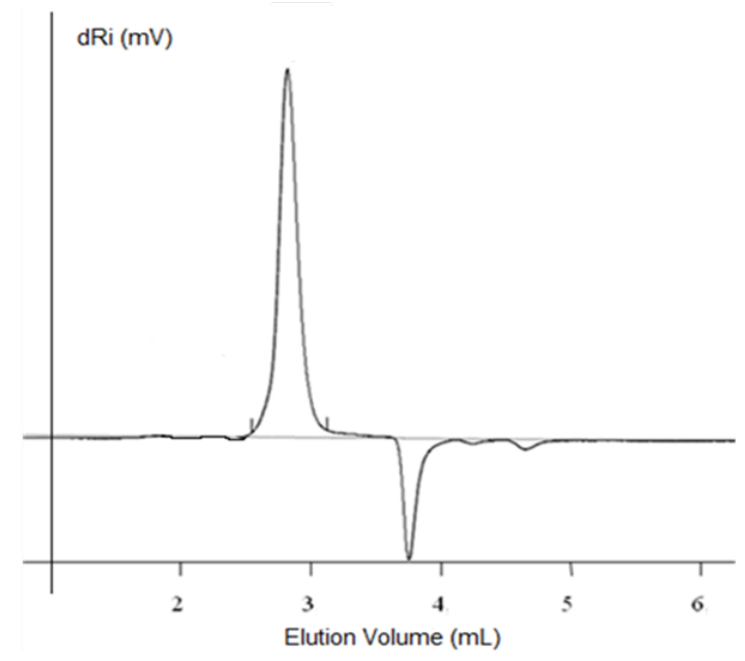

Figure S3. SEC of CD-PEG2 in DMF, $25^{\circ} \mathrm{C}^{21}$ 


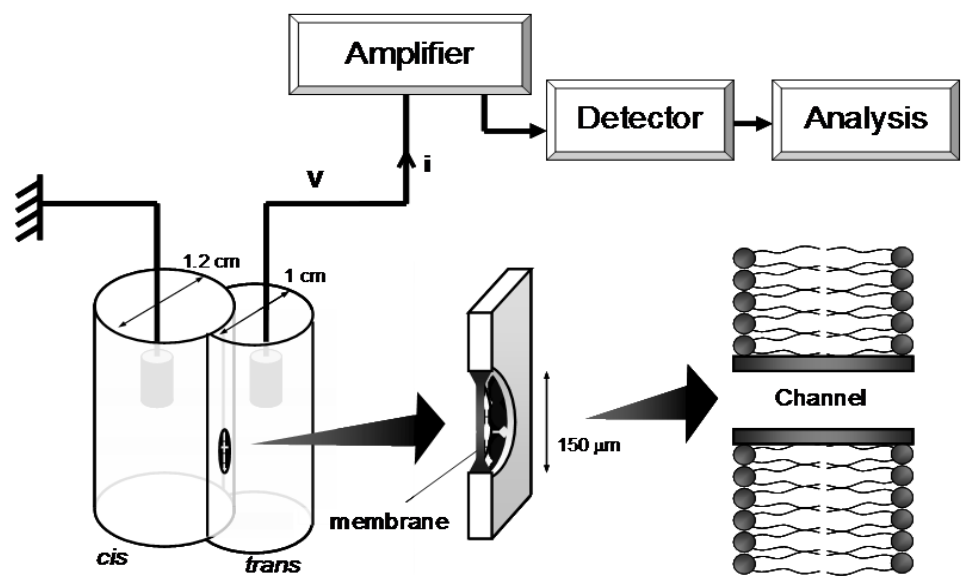

Figure S4. Experimental set-up to allow the evidence of pore formation.

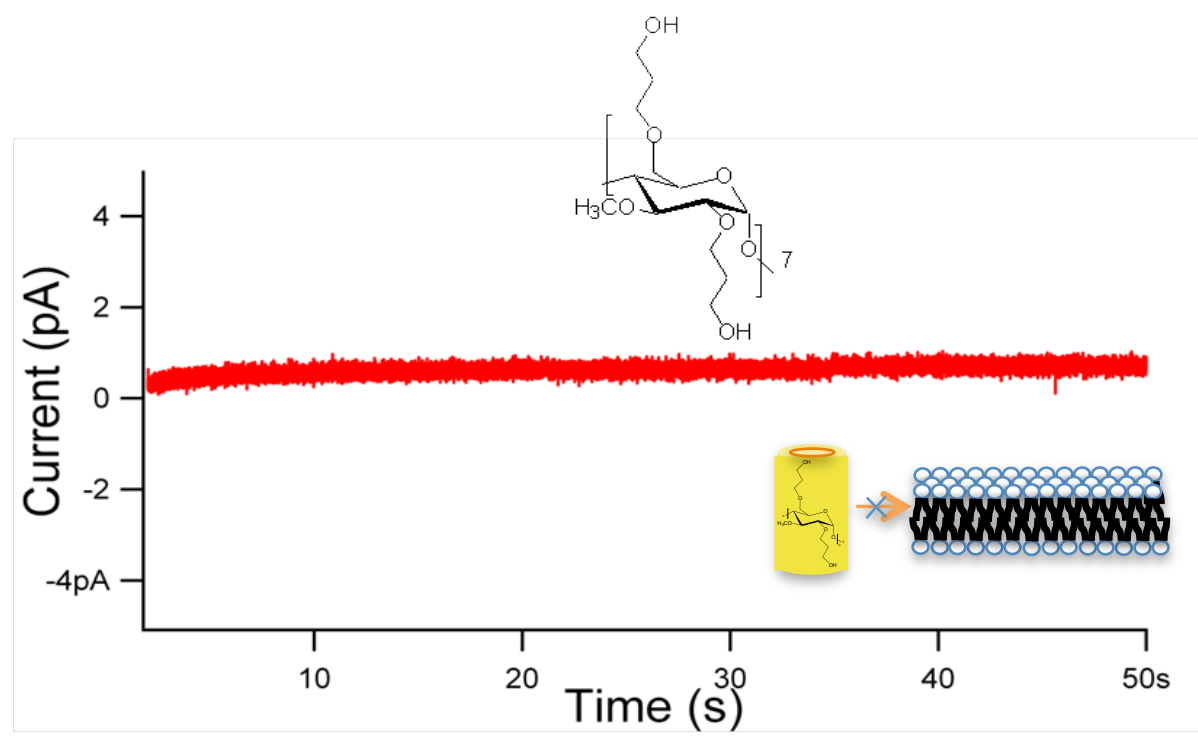

Figure S5. Electrical traces obtained with the initiator, $\operatorname{per}\left(2,6-\right.$ di-O-(3-hydroxypropyl)-3-O-methyl)- $\beta$-CD - $\beta \mathrm{CD}^{\prime}(\mathrm{OH})_{14}$ for an applied voltage of $-100 \mathrm{mV}, \mathrm{KCl} 1 \mathrm{M}$

whatever the concentration of molecules added in both chambers. 

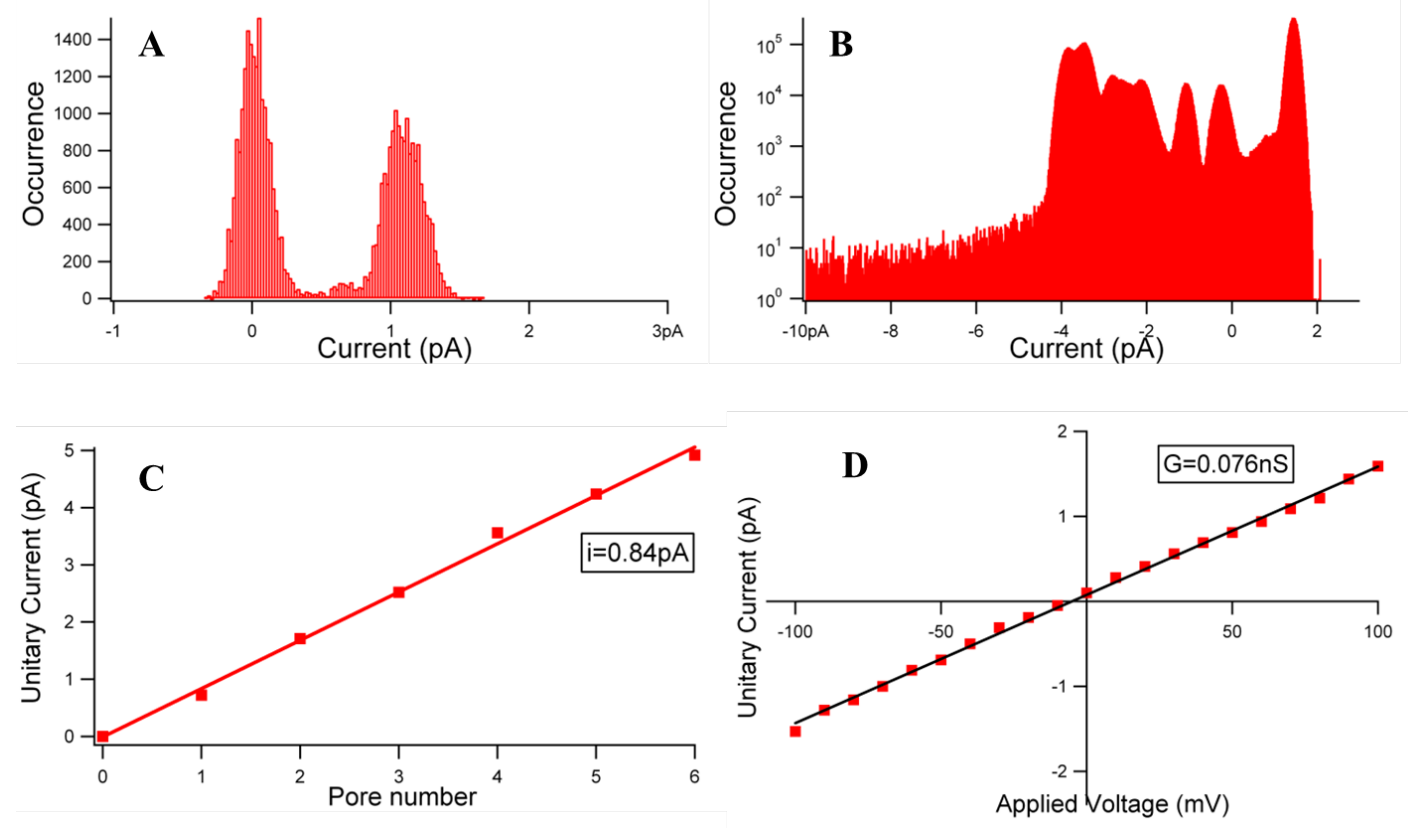

Figure S6. Data analysis obtained for CD-PEG1 $(0.2 \mu \mathrm{M}-\mathrm{KCl} 1 \mathrm{M})$ A-Current distribution of trace A for an applied voltage of $100 \mathrm{mV}$ B-Current distribution of trace B for an applied voltage of $-100 \mathrm{mV}$ $\mathrm{C}$-Current $v s$ pore number, corresponding to trace $\mathrm{B}$

\section{D-I-V curve}
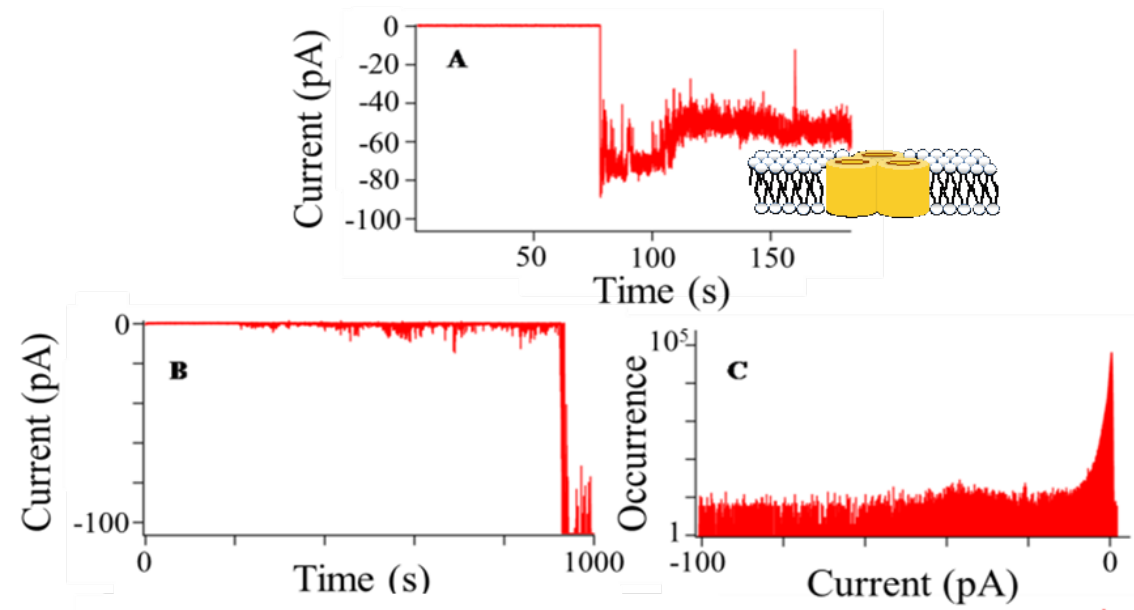

Figure S7. Membrane permeabilization and disruption in presence of CD-PEG2 $(0.2 \mu \mathrm{M}-\mathrm{KCl} 1 \mathrm{M})$

A/B-Current-time traces - applied voltage: $-100 \mathrm{mV}$, C-Current distribution corresponding to the trace $\mathrm{B}$, 

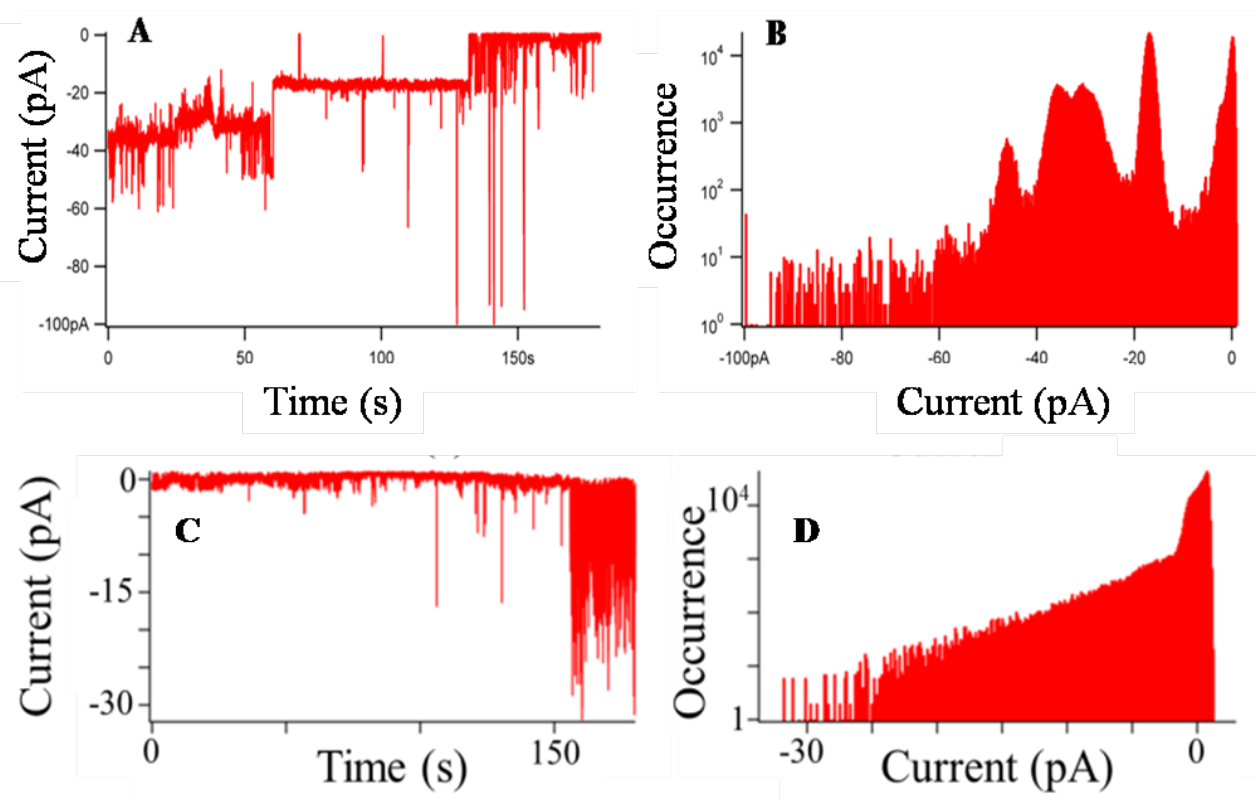

Figure S8. Electrical traces obtained in presence of CD-PEG3

$(0.2 \mu \mathrm{M}-\mathrm{KCl} 1 \mathrm{M})$

A/C-Current-time traces - applied voltage: $-100 \mathrm{mV}$,

$\mathrm{B} / \mathrm{D}$-Current distribution corresponding to the trace $\mathrm{A} / \mathrm{C}$

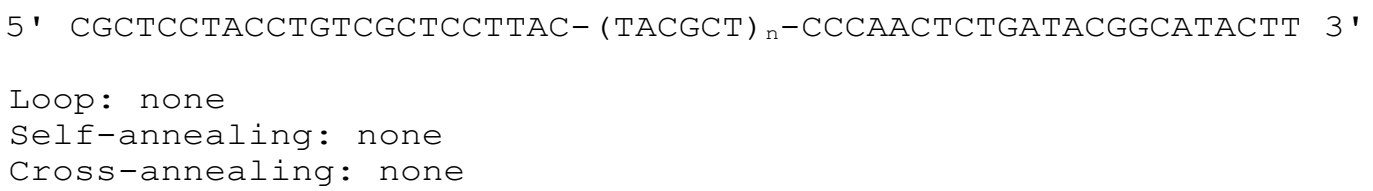

Figure S9. Sequence of the polynucleotideused in translocation experiments $(\mathrm{n}=15)$.

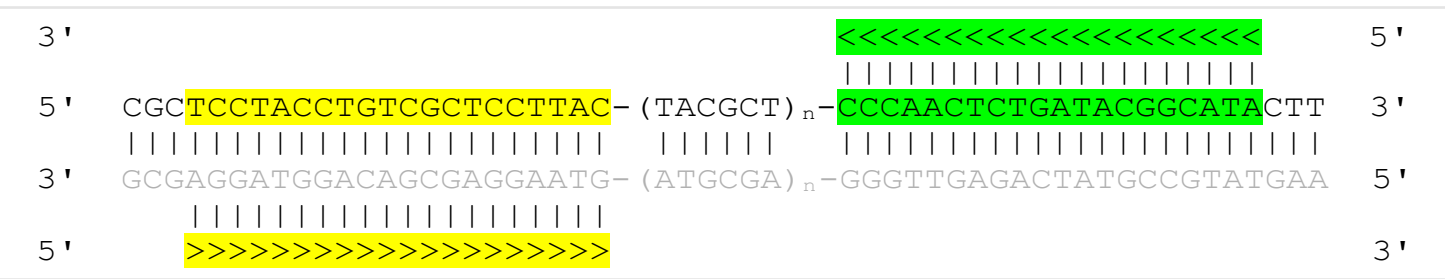

Figure S10. Annealing between the polynucleotide (ssDNAused in translocation experiments) and the primers (in yellow and green) used for its detection via PCR. The complementary sequence shown here in grey was obtained during the $1^{\text {st }} \mathrm{PCR}$ cycle. 
Table 2. Properties of the primers used to detect via PCR the polynucleotide used in translocation experiments.

\begin{tabular}{llllll}
\hline $\begin{array}{l}\text { Strand } \\
(+/-)\end{array}$ & Name & Sequence $\mathbf{( 5}^{\left.\mathbf{\prime}^{\prime} \mathbf{3}^{\prime}\right)}$ & GC\% & $\begin{array}{l}\text { Length } \\
\text { (nt) }\end{array}$ & $\begin{array}{l}\mathbf{T m} \\
\left.\mathbf{(}^{\circ} \mathbf{C}\right)\end{array}$ \\
\hline Forward & F040613 & TCCTACCTGTCGCTCCTTAC & 55 & 20 & 59.3 \\
\hline Reverse & R040613 & TATGCCGTATCAGAGTTGGG & 50 & 20 & 60.9 \\
\hline
\end{tabular}

Tm, primer annealing. Each of these primers does not form any self-annealing or any loop. They can only make some very weak annealing's with each other $(\mathrm{dG}>-1 \mathrm{KCal} / \mathrm{mol})$, without any impact on both sensitivity and efficiency of PCR reactions.
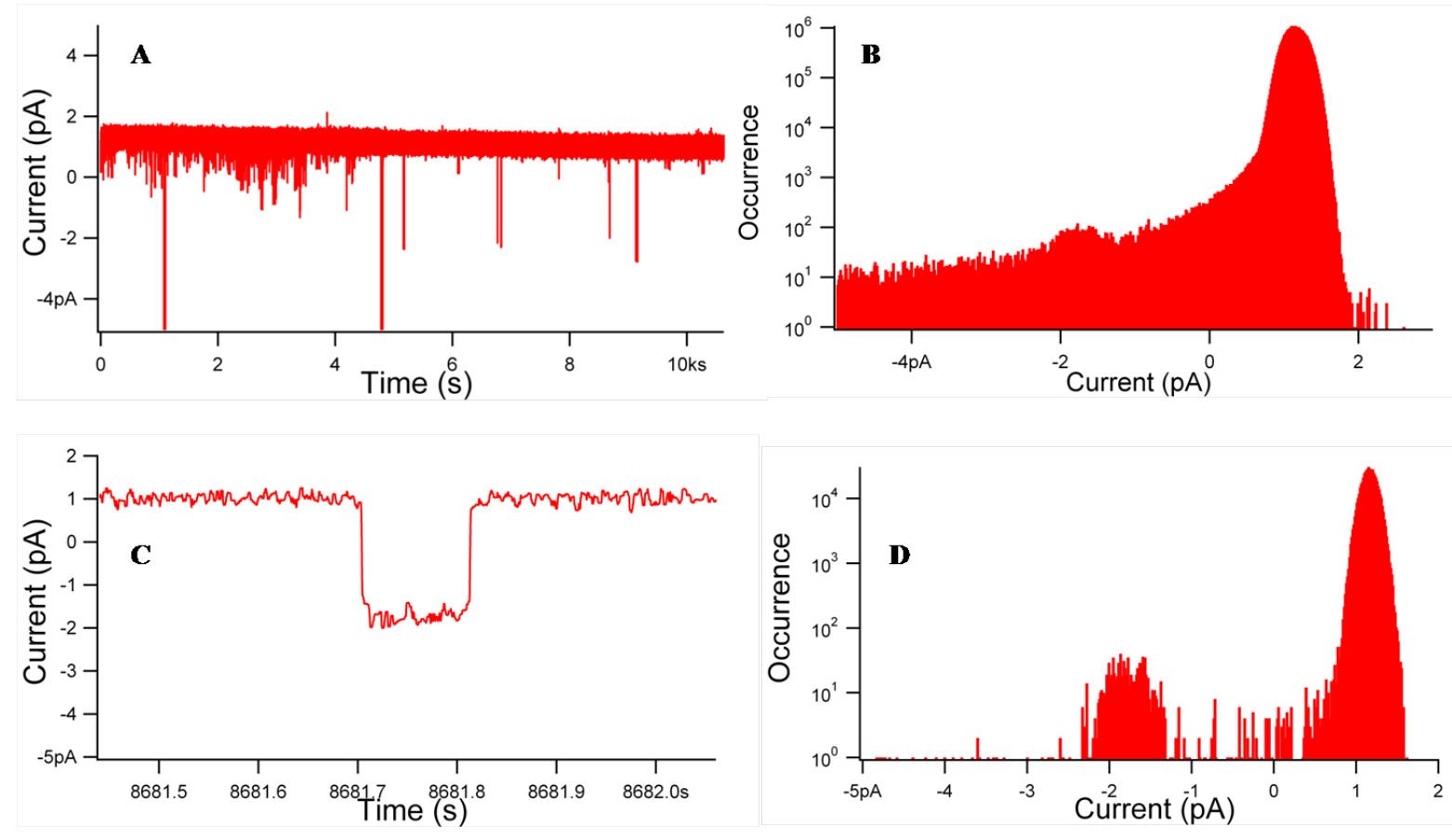

Figure S11. Experiment 2 of translocation (presence of ssDNA in the trans compartment):

Recording of the current versus time, using CD-PEG1, in the presence of ssDNA, for an applied voltage of $-100 \mathrm{mV}, \mathrm{KCl} 3 \mathrm{M}$, at $0.2 \mu \mathrm{M}$

A-Complete current-time trace, witnessing the current increase at various times of the experiment

C-Zoom of trace A, witnessing the presence of discrete signal attributed to the insertion of a synthetic nanopore

$\mathrm{B} / \mathrm{D}-\mathrm{Current}$ distributions corresponding to the traces $\mathrm{A} / \mathrm{C}$ 

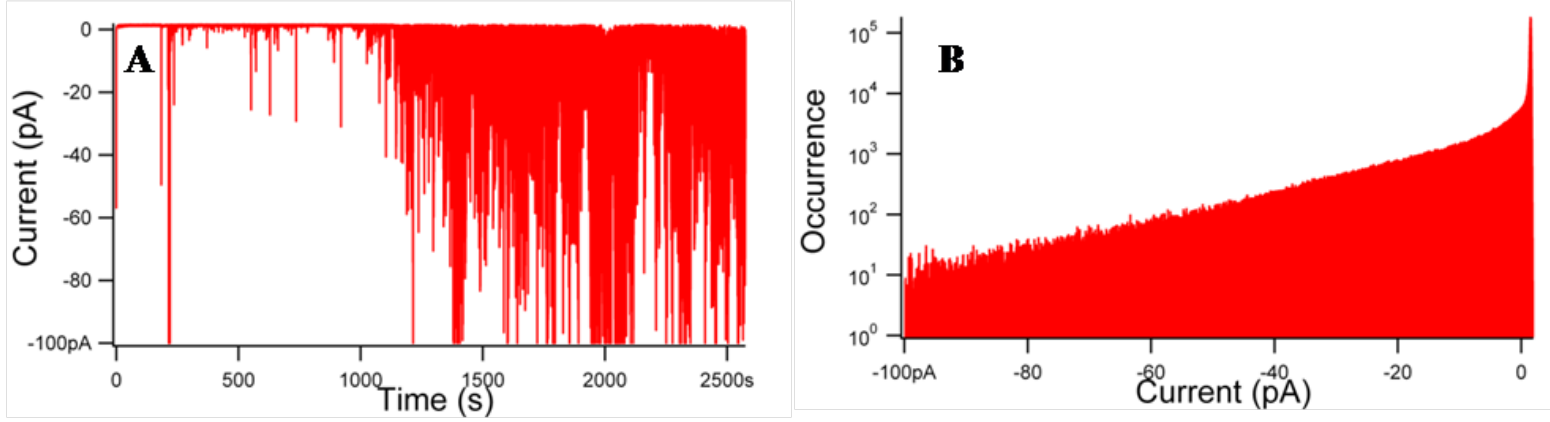

Figure S12. Experiment 3 of translocation (presence of ssDNA in the trans compartment): Recording of the current versus time using CD-PEG1, in the presence of ssDNA, for an applied voltage of $-100 \mathrm{mV}, \mathrm{KCl} 3 \mathrm{M}$, at $0.2 \mu \mathrm{M}$ A-Current-time trace, witnessing the presence of strong interactions B-Current distribution corresponding to the trace A
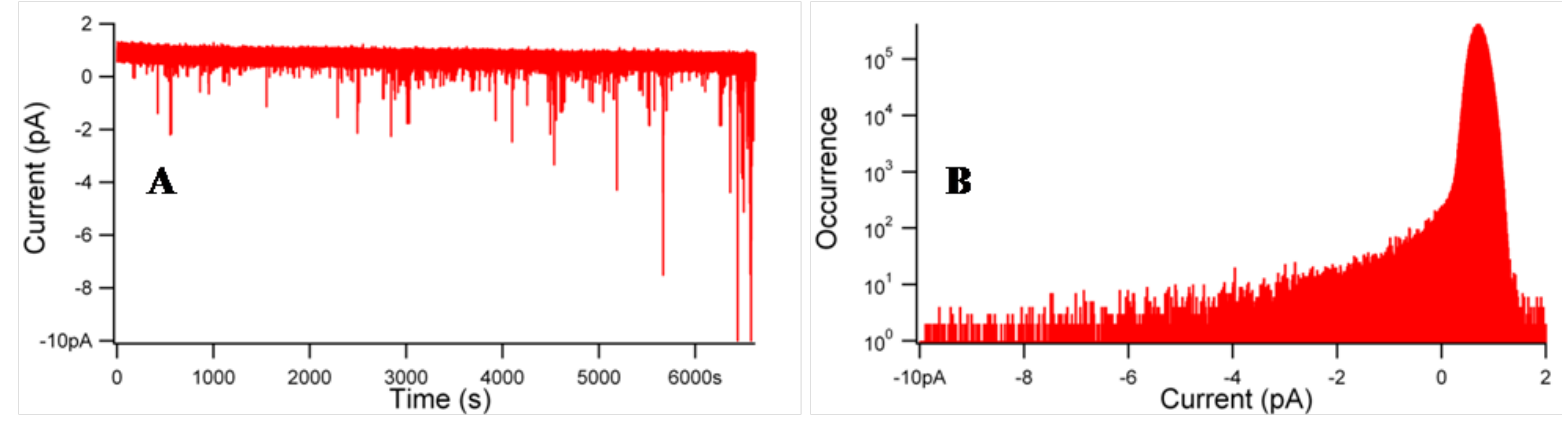

Figure S13. Experiment 4 of translocation (presence of ssDNA in the trans compartment) Recording of the current versus time, using CD-PEG1, in the presence of ssDNA, for an applied voltage of $-100 \mathrm{mV}, \mathrm{KCl} 3 \mathrm{M}$, at $0.2 \mu \mathrm{M}$ A-Current-time trace, witnessing the presence of weak interactions B-Current distribution corresponding to the trace A 